\title{
Communication \\ On the Formation of Micro-Shrinkage Porosities in Ductile Iron Cast Components
}

\author{
Ehsan Ghassemali * (D), Anders E. W. Jarfors (1) and Attila Diószegi \\ Department of Materials and Manufacturing, School of Engineering, Jönköping University, 55111 Jönköping, \\ Sweden; anders.jarfors@ju.se (A.E.W.J.); attila.dioszegi@ju.se (A.D.) \\ * Correspondence: ehsan.ghassemali@ju.se; Tel.: +46-36-10-1692
}

Received: 4 July 2018; Accepted: 16 July 2018; Published: 18 July 2018

\begin{abstract}
A combination of direct austempering after solidification (DAAS) treatment and electron backscatter diffraction (EBSD) method was used to study the formation of micro-shrinkage porosities in ductile iron. Analyzing the aus-ferritic microstructure revealed that most of micro-shrinkage porosities are formed at the retained austenite grain boundaries. There was no obvious correlation between the ferrite grains or graphite nodules and micro-shrinkage porosities. Due to the absolute pressure change at the (purely) shrinkage porosities, the dendrite fragmentation rate during the DAAS process would be altered locally, which caused a relatively finer parent-austenite grain structure near such porosities.
\end{abstract}

Keywords: DAAS; EBSD; shrinkage porosity; austenite; graphite; nodule

\section{Introduction}

It has been reported that during solidification of cast iron, shrinkage of the austenite phase can be compensated by the expansion that is provided by graphite precipitation (for carbon equivalent above $3.6 \%)$ [1]. In reality, however, the shrinkage depends on other factors, such as mold stiffness, pouring temperature, melt composition, and graphite nodule count; thus, the behavior is more complex [2].

According to Stefanescu [3], avoiding macroshrinkage is normally best made by mold design adjustments. However, microshrinkage pores are more complicated and affect not only the mechanical properties, but also sometimes the surface quality of the component [4]. The increasing demand for high performance cast components implies the importance of aesthetically pleasing and structurally sound products. This requires a deep and thorough understanding of the origin of microshrinkage for internal and external soundness of the components.

In cast iron, the microshrinkage is associated with the formation of primary austenite dendrites [3]. Thus, the origin of microsshrinkage can be understood by revealing the retained austenite macrostructure in cast iron. This is done by a treatment, named Direct Austempering After Solidification (DAAS), which was introduced by Rivera et al. [5] and adopted by Elmquist and Dioszegi [4]. This technique has been mostly used for flake or compacted graphite cast iron, but not extensively for nodular graphite (ductile) cast iron.

To reveal the austenitic grain structure after DAAS treatment, mostly color metallography has been used [6]. Using this technique, Tenaglia et al. [7] reported that most shrinkage porosities form intergranularly. The same conclusion was derived by Elmquist and Dioszegi [4]. Using color etching and standard metallography, although it was possible to reveal some features in the microstructure, the results' quality was user-dependent, relying on the etching time and optical light incidence to reveal the grain boundaries. Besides, the presence of porosities could lead to over-etching and/or oxidation around the porosities. 
Alternatively, Electron Backscatter Diffraction (EBSD) can be used for revealing the retained austenite microstructure of DAAS-treated cast iron [8], which provides higher structural resolution and avoids oxidation or over-etching artifacts on the microstructure.

The aim of this study is to investigate and confirm the origin of microshrinkage porosity in ductile iron. A combination of DAAS treatment and the EBSD technique was used on a near-eutectic ductile iron composition, in order to observe the relative location of shrinkage porosities and retained a austenite grain structure.

\section{Materials and Methods}

Ductile iron grade GJS-500-7 was cast in a bathtub-like geometry, as shown schematically in Figure 1a. The geometry was selected as the one containing hot-spot, for producing micro-shrinkages in the component. The composition of the material is shown in Table 1. The spheroidization and inoculations were done using the Tundish cover and in-stream methods, respectively. The nodularity (by area) were $>82 \%$, following ASTM E2567 [8].

Table 1. Chemical composition of the cast material.

\begin{tabular}{ccccccccc}
\hline Element & $\mathbf{C}$ & $\mathbf{S i}$ & $\mathbf{M g}$ & $\mathbf{C u}$ & $\mathbf{M n}$ & $\mathbf{P}$ & $\mathbf{S}$ & $\mathbf{F e}$ \\
\hline wt $\%$ & 3.480 & 2.370 & 0.046 & 0.355 & 0.414 & 0.028 & 0.008 & Balanced \\
\hline
\end{tabular}

The DAAS treatment was done according to the cycle that is shown in Figure 1b. A thermocouple was placed in the sand mold cavity in order to monito the temperature drops for the shake-out stage. After shake-out at around $950{ }^{\circ} \mathrm{C}$, the isothermal heat-treatments at $920{ }^{\circ} \mathrm{C}$ and $360{ }^{\circ} \mathrm{C}$ were done in an electrical furnace and salt bath, respectively. Then the component was cooled down to room temperature in air.

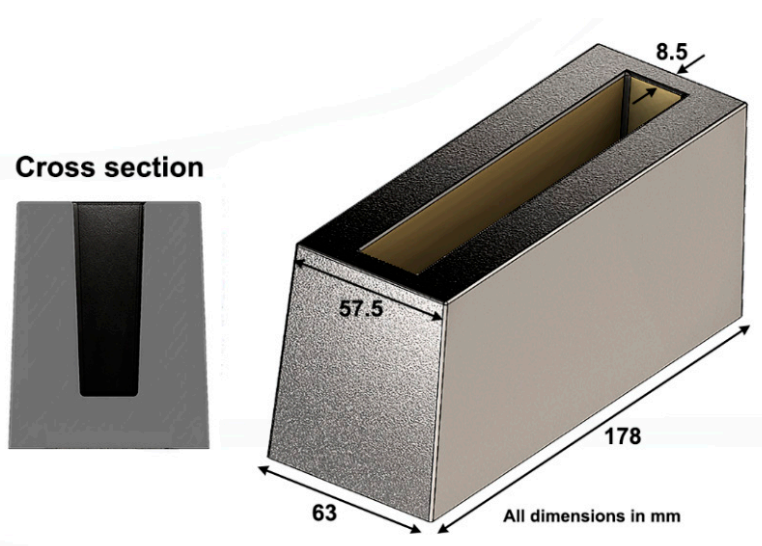

(a)

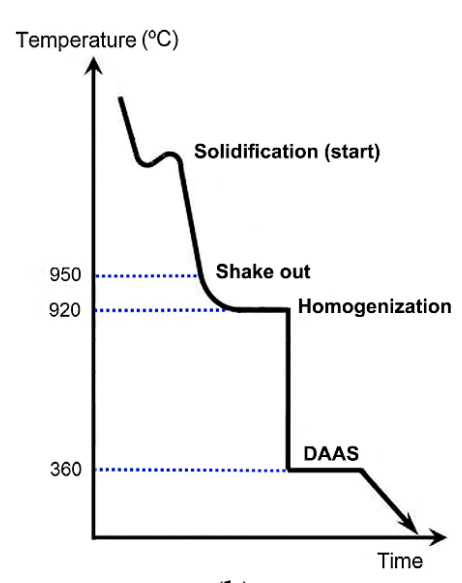

(b)

Figure 1. (a) Schematic of the cast component; and, (b) the Direct Austempering After Solidification (DAAS) treatment procedure.

The component was cut into different sections along the length direction. The EBSD specimens were cut from the "knee" part of the component (see Figure 2a) to investigate micro-shrinkage porosities. Specimens were mechanically grinded and polished down to the $0.04 \mu \mathrm{m}$ oxide polishing suspension (OPS) level. The EBSD acquisition was done using JEOL-7001F (JEOL Ltd., Tokyo, Japan) equipped with EDAX Hikari-Super detector, under $15 \mathrm{kV}$ accelerating voltage and $\sim 5 \mathrm{nA}$ beam current, which led to more than $75 \%$ successful indexing for all of the samples. EBSD data were analyzed using TSL-OIM v.8 (EDAX, Mahwah, NJ, USA). The only post-processing routine applied on EBSD data was the confidence index $(\mathrm{CI})$ standardization. 

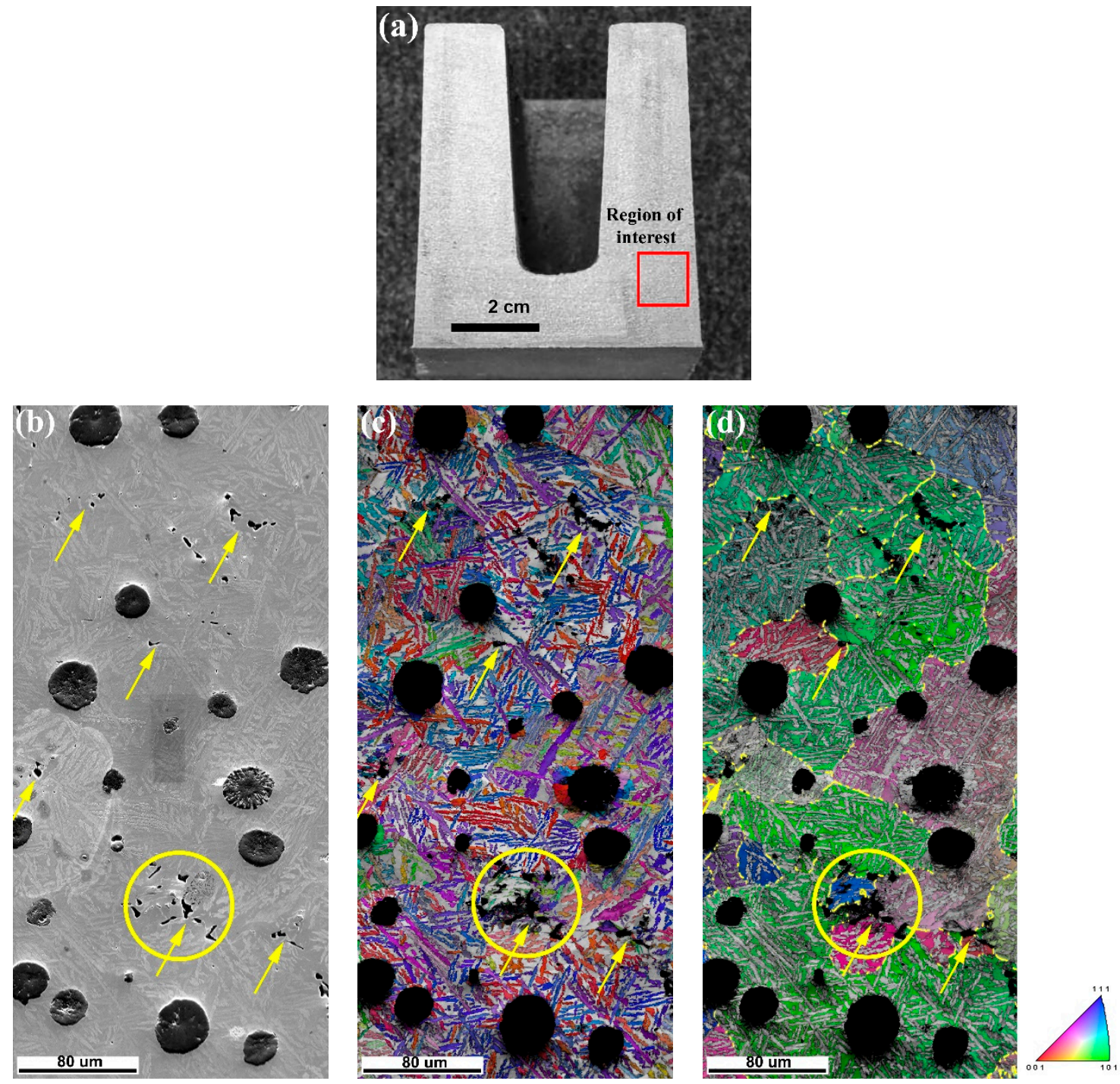

Figure 2. (a) Middle cross section of the "bathtub" component; (b) SEM image of the region of interest (ROI); IPF map of (c) ferrite and (d) austenite phases, over-imposed to the image quality (IQ) map. Austenite high angle grain boundaries (misorientation $>15^{\circ}$ ) are highlighted by yellow lines in (d). Arrows show the micro-shrinkage porosities and circle is highlighting the accumulation of microporosities at the junction of austenite grain boundaries.

\section{Results}

\section{Subsection}

The EBSD analysis of the hot-spot region of the component (highlighted region in the "knee" part of the component; Figure 2a) showed an aus-ferritic microstructure, with an austenite area fraction of around $40 \%$, which is consistent with previous reports [9] (see Figure 2). It is important to note that the misorientation angle between each grain (different color codes in the inverse pole figure (IPF) images) was between $\sim 30^{\circ}$ to $65^{\circ}$. Microshrinkage porosities were obvious in this region, as highlighted by arrows in Figure $2 b$.

As shown, ferritic "needles" were distributed randomly in the microstructure (Figure 2c). Figure $2 \mathrm{~d}$ specifically illustrates the relative location of porosities and austenite grains. Specifically, the accumulated microshrinkage porosities are located at the austenite grain boundaries (highlighted by a circle in Figure $2 b-d$ ). A field analysis showed that most of microshrinkage porosities are located 
at the junctions of the austenite grain boundaries. Only a minute fraction was formed inside the austenite grains. It is important to note that shrinkage porosities normally are a three-dimensional (3D) network of "channels" in the microstructure. Thus, the tail end of a shrinkage network could be seen inside the austenite grain in a two-dimensional image. This requires further investigation using 3D tomography techniques.

It is also important to note that the austenite grain size around these accumulated porosities is rather smaller ( $\sim 60 \%$ smaller) when compared to the rest of the sample. During the DAAS treatment, due to a isothermal coarsening process (after shake-out), dendrite fragmentation could occur, which affects the austenite grain size [10]. The dendrite fragmentation rate mainly depends on the local pressure state in the interdendritic liquid. On the other hand, the coarsening process is an adaptation to the absolute equilibrium. As the melt condition comes closer to the equilibrium pressure state, less porosity would be provoked (smaller accumulated volume of shrinkage), while the retained austenite grains are reduced. Such a situation seems to be more suitable for purely microshrinkage porosities and not gas or gas-shrinkage mixed porosities. This theorem requires further experimental investigation.

In addition, the possible elemental segregation in the last solidifying area (hot spot) can lead to partial and local changes in the thermal gradient and thus affects the local cooling rate and consequently the grain size near shrinkage porosities.

Figure 3 represents areas with relatively larger shrinkage pores, which could be gas-shrinkage mixed porosities, according to their morphology. As shown, most of porosities, regardless of their size, were formed at the retained austenite grain boundaries, Figure 3c. There seems to be no direct relationship between the ferrite grains and shrinkage porosities, since the ferrite phase has formed through a solid-state transformation. However, as reported before [11], there is an orientation relationship between austenite and ferrite grains in the aus-ferritic structure; hence, implying the indirect effect of ferrite on the porosity formation, which requires deeper studies.
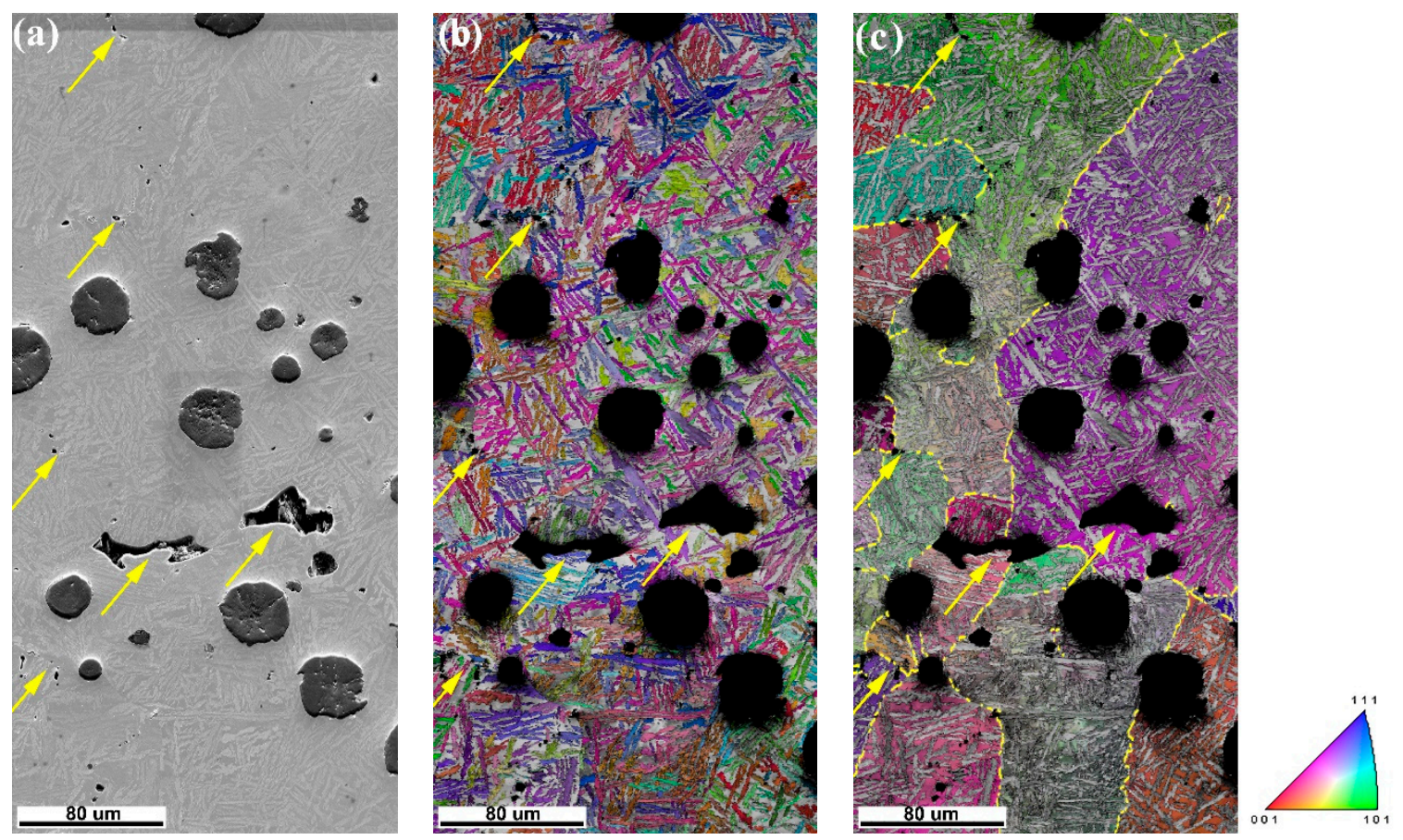

Figure 3. Electron Backscatter Diffraction (EBSD) analysis of another ROI from the same area in the component; (a) SEM micrograph; IPF map of (b) ferrite; and, (c) austenite phases, over-imposed to the image quality (IQ) map. Austenite high angle grain boundaries (misorientation $>15^{\circ}$ ) are highlighted by yellow lines in (c). Arrows show micro-shrinkage porosities. 


\section{Conclusions}

The microshrinkage porosity formation in ductile iron was investigated using DAAS treatment and EBSD analysis. The main outcomes of this study can be summarized as:

- A direct correlation between austenite grain boundaries and shrinkage porosities was observed. Most of micro-shrinkage porosities were located at the austenite grain boundaries. There was a minute fraction of porosities being located inside the austenite grains, which could be due to the 3D network of porosities and needs further investigation.

- $\quad$ Some shrinkage porosities appeared to be associated with finer retained austentite grains in the vicinity, which was correlated with the equilibrium state and its effect on dendrite fragmentation during the solidification process. The suggested hypothesis was assumed to be correct for "pure" shrinkage porosity (not a gas-shrinkage mixted porosity).

- No direct relationship between ferrite grains and microshrinkage porosities were observed in this study.

- Although the effect of shrinkage porosity on overall mechanical properties of ductile iron has been studied before, its effect on the crack initiation and propagation in the microstructural level can be further investigated using in-situ SEM techniques.

Author Contributions: Conceptualization of the paper was made by A.D., E.G. and A.E.W.J. The experimental work was made by E.G. and A.E.W.J. The EBSD analysis was made by E.G. Writing-Review \& Editing was made by E.G., A.D. and A.E.W.J.

Funding: The authors acknowledge the Knowledge Foundation for financial support under the CompCAST project (20100280).

Acknowledgments: The authors would like to acknowledge Arvika Gjuteri AB for providing the cast material and providing access to their foundry for the experiments. Keivan A. Kasvayee and Jörgen Bloom are acknowledged for the support during the casting experiments at Arvika Gjuteri AB.

Conflicts of Interest: The authors declare no conflict of interest. The funders had no role in the design of the study; in the collection, analyses, or interpretation of data; in the writing of the manuscript, and in the decision to publish the results.

\section{References}

1. Campbell, J. Castings; Elsevier Science: New York, NY, USA, 2003.

2. Kanno, T. Effect of pouring temperature, composition, mould strength and metal flow resistance on shrinkage cavities in spheroidal graphite cast iron. Int. J. Cast Met. Res. 2008, 21, 2-6. [CrossRef]

3. Stefanescu, D.M. Science and Engineering of Casting Solidification, 2nd ed.; Springer: San Francisco, CA, USA, 2009.

4. Elmquist, L.; Diószegi, A. Shrinkage porosity and its relation to solidification structure of grey cast iron parts. Int. J. Cast Met. Res. 2010, 23, 44-50. [CrossRef]

5. Rivera, G.L.; Boeri, R.E.; Sikora, J.A. Solidification of gray cast iron. Scr. Mater. 2004, 50, 331-335. [CrossRef]

6. López, M.G.; Rivera, G.L.; Massone, J.M.; Boeri, R.E. Study of the solidification structure of compacted graphite cast iron. Int. J. Cast Met. Res. 2016, 29, 266-271. [CrossRef]

7. Tenaglia, N.; Boeri, R.; Rivera, G.; Massone, J. Study of shrinkage porosity in spheroidal graphite cast iron. Int. J. Cast Met. Res. 2016, 29, 112-120. [CrossRef]

8. ASTM. Standard Test Method for Determining Nodularity and Nodule Count in Ductile Iron Using Image Analysis; ASTM E2567-16A; ASTM International: West Conshohocken, PA, USA, 2016.

9. Rivera, G.; Calvillo, P.R.; Boeri, R.; Houbaert, Y.; Sikora, J. Examination of the solidification macrostructure of spheroidal and flake graphite cast irons using daas and esbd. Mater. Charact. 2008, 59, 1342-1348. [CrossRef] 
10. Hernando, J.C.; Ghassemali, E.; Diószegi, A. The morphological evolution of primary austenite during isothermal coarsening. Mater. Charact. 2017, 131, 492-499. [CrossRef]

11. Headley, T.J.; Brooks, J.A. A new bcc-fcc orientation relationship observed between. Metall. Mater. Trans. A 2002, 33A, 11. 